\title{
Small-scale spatial variation of meiofaunal communities in Lima estuary (NW Portugal) assessed through metabarcoding
}

\author{
Maria Fais ${ }^{a, b, c, *}$, Sofia Duarte ${ }^{\mathrm{a}, \mathrm{b}}$, Pedro Emanuel Vieira ${ }^{\mathrm{a}, \mathrm{b}}$, Ronaldo Sousa ${ }^{\mathrm{a}, \mathrm{b}}$, \\ Mehrdad Hajibabaei $^{\mathrm{d}}$, Carlos Alberto Canchaya ${ }^{\mathrm{c}}$, Filipe Oliveira Costa ${ }^{\mathrm{a}, \mathrm{b},{ }^{* *}}$

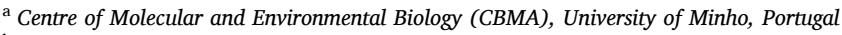 \\ ${ }^{\mathrm{b}}$ Institute of Science and Innovation for Bio-Sustainability (IB-S), University of Minho, Portugal \\ ${ }^{\mathrm{c}}$ Department of Biochemistry, Genetics and Immunology, University of Vigo, Spain \\ ${ }^{\mathrm{d}}$ Centre for Biodiversity Genomics and Department of Integrative Biology, University of Guelph, Canada
}

\section{A R T I C L E I N F O}

\section{Keywords:}

Meiofauna

Estuaries

DNA metabarcoding

Intertidal variation

Patchiness

Protocol optimisation

\begin{abstract}
A B S T R A C T
Meiofaunal organisms play a key role in estuarine ecosystems, being responsible for significant ecological processes. However, meiofauna constitutes a particularly difficult community to be monitored through conventional morphology-based approaches. New emerging tools, such as DNA metabarcoding, facilitate the access to these communities and provide an opportunity to develop routine monitoring programs. In the present study, the small-scale spatial variation of meiofaunal communities in the Lima estuary (NW Portugal) was investigated using DNA metabarcoding. The first stage of the study aimed to establish the amount of sediment sample to be used for DNA extraction and to test six primer pairs, three of them amplifying fragments from the mitochondrial cytochrome $c$ oxidase gene (COI) and three other the nuclear ribosomal 18S rRNA gene (18S). In a subsequent stage, sediment samples were collected in four stations along an estuarine gradient (salinity ranging between 9 and 28), in which six sampling points about 4-5 $\mathrm{m}$ apart were considered: three in the high intertidal and three in the mid intertidal. After the DNA extraction from sediments, COI and 18S amplicon libraries were produced and sequenced in an Illumina MiSeq platform. OTUs (operational taxonomic units) recovered by either COI or $18 \mathrm{~S}$ displayed generally high turnover in occurrence among sampling points within a station and tidal horizon, among tidal horizons within a station, and among stations of distinct salinity (approx. 60-93\%). Both markers recorded little variation among stations in OTU richness and in the taxonomic composition of the most dominant groups. However, the meiofauna detected differed qualitatively between the two markers used; Amoebozoa and Cnidaria were mostly detected with COI while Ciliophora and Platyhelminthes with 18S. In addition, the structure of the meiofauna community diverged significantly among stations and was strongly influenced by salinity and sediment features. Globally, results indicated a highly patchy distribution of meiofauna taxa in the Lima estuary, revealed by the high OTU turnover even between sampling points only a few meters apart. Hence, eDNA-based meiofauna surveys require consideration of the necessary sampling effort on relatively small spatial scales, as well as an appreciation of the tidal level-induced variation of these communities.
\end{abstract}

\section{Introduction}

Estuarine environments are extremely relevant due to their high productivity, richness in habitats and biotas, and for being responsible for fundamental ecosystem processes and functions (Day et al., 2012; Savage et al., 2012). Estuaries have been increasingly disturbed by multiple anthropic activities (e.g., habitat loss and fragmentation, pollution, climate change, introduction of non-native species and overexploitation of resources), which may pose at risk the structure of biological communities and ecosystem functioning, as well as the services provided (Schratzberger and Ingels, 2018). Some of the most inconspicuous benthic groups in estuaries are frequently underestimated or overlooked by commonly used biomonitoring approaches, despite their roles in trophic and non-trophic processes, and their rapid response to environmental disturbances (Zeppilli et al., 2015; Sweetman et al., 2017; Schratzberger and Ingels, 2018; Zeppilli and Leduc, 2018). Among

\footnotetext{
* Corresponding author. Centre of Molecular and Environmental Biology (CBMA), University of Minho, Campus de Gualtar, 4710-057, Braga, Portugal.

** Corresponding author. Centre of Molecular and Environmental Biology (CBMA), University of Minho, Campus de Gualtar, 4710-057, Braga, Portugal.

E-mail addresses: maria.fais@bio.uminho.pt (M. Fais), fcosta@bio.uminho.pt (F.O. Costa).
} 
them, meiofauna has received less attention than the larger and more easily studied macrofauna (Zeppilli and Leduc, 2018), in spite of its role in nutrient cycling and provision of food to higher trophic levels (Schratzberger and Ingels, 2018; Zeppilli and Leduc, 2018).

Meiofaunal organisms comprise a group of benthic organisms included between the micro- and the macrobenthos, which are traditionally sorted by the sieving procedure (Mare, 1942). Meiofauna range size may vary from a minimum of 30-63 $\mu \mathrm{m}$ to a maximum of $0.5-1 \mathrm{~mm}$ (Giere, 2009; Somerfield and Warwick, 2013). However, this constitutes only an operational definition, since some taxa can be greater or smaller than the size ranges indicated above (McIntyre, 1969; Higgins and Thiel, 1988). Indeed, meiofauna comprises both small marine metazoans and large protists (i.e., the permanent meiofauna), as well as the so-called temporary meiofauna, such as juvenile stages of crustaceans, molluscs, annelids and thalassobiontes (McIntyre, 1969; Coull and Chandler, 2019; Giere, 2009; Higgins and Thiel, 1988). Meiofaunal organisms have ease of dispersal and short half-life (Coull, 1999), high abundance and diversity, rapid generation times and high metabolic rates (Zeppilli and Leduc, 2018). They are assumed to have ubiquitous distribution, controlled solely by environmental factors, according to the EiE hypothesis: "everything is everywhere, but the environment selects" (Baas-Becking, 1934; O'Malley, 2008; Fontaneto et al., 2011). Nonetheless, the extensive and comprehensive monitoring of meiofaunal biodiversity has been hampered both by its bioecological characteristics (i.e., small size, presence of sibling species, high intraspecific variability; Tang et al., 2012; Fontaneto et al., 2015; Leasi et al., 2016; Leasi et al., 2018), and the lack of experts in meiobenthos taxonomy (Creer et al., 2010, 2016; Guardiola et al., 2015).

The recent emergence of DNA metabarcoding facilitated considerably the access to the investigation and monitoring of meiofauna communities (Lallias et al., 2015; Haenel et al., 2017; Faria et al., 2018; Leasi et al., 2018). Among other, metabarcoding-based studies have contributed to a better understanding of the "meiofaunal paradox" (Giere, 2009 and reference therein), which perceives meiofauna as comprising both cosmopolitan and narrow-range endemic species, eventually clarifying some supposedly wide distributions of meiofaunal taxa (Fonseca et al., 2014; Lallias et al., 2015; Leasi et al., 2016). Nevertheless, the comparison of data obtained through metabarcoding with information derived from morphology-based approaches can also be challenging, as the resolution and depth of analysis is different, and cryptic diversity may further complicate comparability (Coissac et al., 2012; Creer et al., 2016; Cristescu and Hebert, 2018).

Some weaknesses have been identified in the DNA metabarcoding approach which may affect the ecological interpretation of sequence data, including the presence of false positives produced by DNA amplification and sequencing biases (Ficetola et al., 2015, 2016), insufficiencies in experimental design and sample size employed (Cristescu, 2014; Brannock and Halanych, 2015; Nascimento et al., 2018), composition bias originated by the choice marker loci and primer pairs (Cristescu, 2014; Carugati et al., 2015; Deiner et al., 2015; Sinniger et al., 2016) and inconstancy of procedures for sequence data treatment (Flynn et al., 2015; Clare et al., 2016; Goldberg et al., 2016). These biases can influence the number and the quality of data necessary to determine accurately the taxonomic composition of the studied communities. Hence, important technical hurdles must be first overcome to obtain robust protocols for the assessment of meiobenthic communities.

In the current study, a two-stage approach was designed to tackle some of the challenges that may arise when employing DNA metabarcoding for assessing the diversity of estuarine meiofauna. Our specific aims were to: 1) optimize several elements of the DNA metabarcoding workflow applied to meiofaunal communities, namely the amount of sediment used for DNA extraction and preferential markers and primer pairs to use; and 2) investigate the small-scale spatial variation of meiofauna communities within an estuary, including between sampling points a few meters apart, between tidal levels, and between sites along an estuarine gradient. For this purpose, we used as study system the Lima Estuary, located in the Atlantic coast of NW Iberia, which can be characterized as an average size estuary with low anthropogenic disturbance (Sousa et al., 2006, 2007).

\section{Material and methods}

\subsection{Experimental design}

The current study was conducted in two stages. The first one focused on protocol optimisation, namely to assess the influence of the amount of sediment used for DNA extraction $(0.5,2.5$ and $10.0 \mathrm{~g})$ as well as marker [mitochondrial cytochrome $c$ oxidase I (COI) and the nuclear small sub-unit rRNA gene (18S)] and primer used (three internal regions of the COI barcode region and three hypervariable regions of the 18S: V1-V2, V4 and V9) on the richness and diversity of meiofauna taxa recorded. The second stage addressed the spatial variation of meiobenthic communities within and between four sampling stations in Lima estuary, using the sediment amount and the most efficient primer pairs selected in stage I.

\subsection{Sample collection and preservation}

\subsubsection{Stage I: Optimisation of protocols}

Two sampling stations were selected for the optimisation of protocols in the stage I (Table 1): downstream, under mixoeuhaline conditions (Darque, DAR, salinity: 34.00), and upstream with mesohaline conditions (Serreleis, SER, salinity: 6.15). In June 2016, the first $8 \mathrm{~cm}$ of sediments were collected with PVC corers $(10 \mathrm{~cm} \emptyset)$, and placed immediately on dry ice for transportation to the laboratory, where they were stored in Falcon ${ }^{\circledR}$ tubes at $-20{ }^{\circ} \mathrm{C}$ until DNA extraction. Salinity was measured at both sampling stations using a field probe (Multiparameter Sea Gauge YSI EXO 2) in the water surface in the lower tidal zone.

\subsubsection{Stage II: Spatial variation}

The second stage involved sampling in four stations in Lima estuary in June 2017, which included the two described in section 2.2.1, and two other intermediate stations: Meadela (MEA) and Santa Marta de Portuzelo (POR; Table 1; Fig. S1). The first $5 \mathrm{~cm}$ of sediment were collected directly to $50 \mathrm{~mL}$ sterile Falcon $₫$ tubes $(3 \mathrm{~cm} \varnothing)$, transported on dry ice to the laboratory, and stored at $-20{ }^{\circ} \mathrm{C}$ until subsequent DNA extractions. At each station, three sampling points about 4-5 m apart were considered in each tidal level: the high and middle intertidal zones. Additional sediment samples were taken at each sampling station and intertidal zone to determine sediment grain size (Table S1) and total organic matter (TOM; Table S2).

\subsection{DNA extraction, amplification and HTS procedures}

\subsubsection{Stage I: Optimisation of protocols}

Three different amounts of sediment ( $0.5 \mathrm{~g}, 2.5 \mathrm{~g}$ and $10.0 \mathrm{~g}$ ) were used to test the influence of the sediments sample size on the number of Operational Taxonomic Units (OTUs) recovered and taxonomic composition of meiobenthic communities. In order to reduce as much as possible the loss of important taxa, such as protists and smaller or softbodied eukaryotes (Fonseca et al., 2010; Carugati et al., 2015; Nascimento et al., 2018), the DNA was extracted directly from the sediments using the MoBio ${ }^{\circledR}$ DNA Isolation kits (PowerSoil cat\#12888-100 for the $0.5 \mathrm{~g}$ amount; PowerMax cat\#12988-10 for 2.5 and $10.0 \mathrm{~g}$ amounts). Extraction procedures followed manufacturer's instructions except for the usage of a multi-tube vortex during the lysis step, and setting up of the posterior centrifugation to $5 \mathrm{~min}$.

The production of amplicon libraries and the high-throughput sequencing (HTS) were carried out at Genoinseq (Biocant, Cantanhede, Portugal), as described below. Six different primer pairs were used to generate the amplicons to be analysed by HTS (Table S3). Three 
Table 1

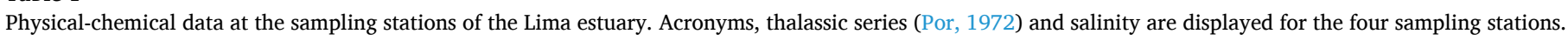

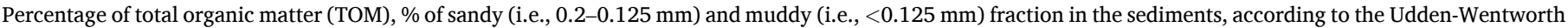
scale (Udden, 1914; Wentworth, 1922), in the high intertidal zone (high) and middle intertidal zone (mid), for each sampling station.

\begin{tabular}{|c|c|c|c|c|c|}
\hline & Intertidal zone & Darque & Meadela & Santa Marta de Portuzelo & Serreleis \\
\hline Sampling station acronym & & DAR & MEA & POR & SER \\
\hline \multirow[t]{2}{*}{ Coordinates } & lat & $41^{\circ} 68^{\prime} 33^{\prime \prime} \mathrm{N}$ & $41^{\circ} 69^{\prime} 51^{\prime \prime} \mathrm{N}$ & $41^{\circ} 69^{\prime} 78^{\prime \prime} \mathrm{N}$ & $41^{\circ} 70^{\prime} 08^{\prime \prime} \mathrm{N}$ \\
\hline & lon & $08^{\circ} 82^{\prime} 76^{\prime \prime} \mathrm{W}$ & $08^{\circ} 81^{\prime} 12^{\prime \prime} \mathrm{W}$ & $08^{\circ} 77^{\prime} 18^{\prime} W$ & $08^{\circ} 74^{\prime} 93^{\prime \prime} \mathrm{W}$ \\
\hline Thalassic series & & mixoeuhaline & mesohaline & mesohaline & mesohaline \\
\hline Salinity & & 28.31 & 15.84 & 9.10 & 11.42 \\
\hline \multirow[t]{2}{*}{$\%$ TOM } & high & 1.64 & 3.79 & 6.71 & 3.46 \\
\hline & mid & 0.85 & 1.72 & 4.63 & 1.39 \\
\hline \multirow[t]{2}{*}{$\%$ of sandy sediments } & high & 80.04 & 61.19 & 59.63 & 65.72 \\
\hline & mid & 84.24 & 70.56 & 77.96 & 68.04 \\
\hline \multirow[t]{2}{*}{$\%$ of muddy sediments } & high & 10.33 & 1.35 & 6.29 & 0.21 \\
\hline & mid & 13.14 & 0.51 & 4.64 & 0.36 \\
\hline
\end{tabular}

primer pairs targeted the COI gene, here coded as COI-A (313 bp; Leray et al., 2013; Lobo et al., 2013), COI-B (310 bp; Gibson et al., 2014) and COI-C (250 bp; Lobo et al., 2013; Gibson et al., 2014). Other three aimed an equal number of regions of the $18 \mathrm{~S}$ rRNA gene: V1-V2 ( $400 \mathrm{bp}$; Creer et al., 2010), V4 ( 400 bp; Stoeck et al., 2010; Lejzerowicz et al., 2015) and V9 ( 200 bp; Hardy et al., 2010). For each sample and primer pair, negative controls were included in the amplification reactions, and the resultant products were one-step purified, normalized and pooled. Amplicons were sequenced in an Illumina MiSeq platform according to standard procedures. The complete list of primer pairs, their approximate amplicon length and location within the respective marker, as well as detailed PCR amplification and HTS procedures, are available in Tables S3 and S4.

\subsubsection{Stage II: Spatial variation}

DNA was extracted from $10.0 \mathrm{~g}$ of sediment from each of the 24 samples collected, using the QIAGEN ${ }^{\circledR}$ PowerMax Isolation kit (cat\#12988-10), following the manufacturer's instructions and procedures as in 2.3.1. The MoBio extraction kits used in the optimisation stage (stage I) were no longer available because they were acquired by QIAGEN in the meantime. However, the QIAGEN kit uses exactly the same components of the MoBio kit, and was certified by QIAGEN to provide comparable results. Since COI-A and V4 significantly resulted in a greater number of OTUs attributed to meiofauna compared to the other primer pairs (see section 3.1), they were selected in the stage II to evaluate the small-scale variation of the meiofauna community. Amplicon library preparation and HTS sequencing of COI-A and V4 was performed as described in 2.3.1.

\subsection{Bioinformatics pipeline}

The forward-R1 and reverse-R2 reads generated by HTS were merged and sorted-out using customized procedures in mothur v.1.39.5 (Schloss et al., 2009; Kozich et al., 2013) to remove primers, reduce sequencing biases and PCR errors, and de-replicate redundant reads. The detection and discard of chimeras and the de novo OTU clustering at $97 \%$ similarity were performed using VSEARCH (Rognes et al., 2016) algorithm encoded in mothur. In order to ascertain the effect of the sediment amount on OTU and taxa richness, the number of useable reads under comparison was equalized by downsampling to the lowest read number using mothur. However, as this procedure is susceptible to distortions when using abundance data, namely creating false positives (McMurdie and Holmes, 2014), this step was not applied in the second stage of the experiment. OTUs with rare sequences (i.e., less than 9) were excluded in both stages, following Leray and Knowlton (2017) suggestion, to avoid sequencing artefacts not detected in previous data processing steps. In addition, OTUs detected in only one sample (here identified as singleton OTUs) were removed in order to avoid cross-talk errors on diversity estimation (Majaneva et al., 2015; Edgar and Flyvbjerg, 2018).

The representative sequences of each OTU (i.e., the unique sequence in a data set clustered by the highest abundance of the centroid; Rognes et al., 2016) were BLASTed against the non-redundant nucleotide (nt) GenBank ${ }^{\circledR}$ library (Benson et al., 2018) with the following settings: evalue $1 \mathrm{e}^{-30}$, -max_target_seqs 50 , -perc_identity 70 . The top 50 matches were kept for subsequent taxonomic assignment to the lowest possible rank in MEGAN v.6.13.1 (Huson et al., 2016), following Weigand and Macher (2018). The nomenclature was verified manually in both the World Register of Marine Species (WoRMS) and National Centre for Biotechnology Information (NCBI) databases. Only the OTUs attributed to the meiofaunal groups, sensu Giere (2009), were used in subsequent analyses.

OTU rarefaction for stage I and II and accumulation curves for stage II were determined separately for all OTUs and for meiofauna OTUs in RStudio v. February 1, 1335 (RStudio Team, 2018) with the vegan package (Oksanen et al., 2013). Raw sequencing data of each data-set was deposited in the Sequence Read Archive (SRA) of NCBI (http s://www.ncbi.nlm.nih.gov/sra/) in the BioProject PRJNA611064.

\subsection{Data analyses}

For stage I, meiofauna OTU richness and the proportion of OTU recorded by phylum were determined for each combination of primer pairs and amount of sediment employed, and averaged between the two sampling stations. A two-way ANOVA was used to assess the effect of the amount of sediment and primer pair on the number of meiofauna OTUs recovered (GraphPad Software, Inc.).

For stage II, the proportion of overlapping OTUs (excluding singleton OTUs) was determined for each primer, within and between stations, and between intertidal zones, using the venn algorithm in mothur (Schloss et al., 2009; Kozich et al., 2013). The data were subsequently interpreted as OTU turnover, i.e., the proportion of different OTUs replaced within and between stations, and between intertidal zones, and displayed in bar-graphs (GraphPad Software, Inc.). OTU richness was determined for each intertidal level and locus, verified for normality, and displayed as the average of 3 sampling points for each intertidal level, within each station. A two-way ANOVA was used to assess the effect of intertidal level and sampling station in the number of recovered meiofauna OTUs (GraphPad Software, Inc.). Bray-Curtis measure of dissimilarity for each primer pair was calculated with the vegdist function in the R vegan package (Oksanen et al., 2013) to investigate meiofauna community's structure through hierarchical clustering [hclust function with average linkage method; RStudio team (2018)]. A multivariate ANOVA based on dissimilarities (PERMANOVA) was tested by the adonis function (method: Bray-Curtis; $\mathrm{n}^{\circ}$ of permutations: 1000) in the $\mathrm{R}$ vegan package (Oksanen et al., 2013), to assess the effects of intertidal zone (two factors: high and mid intertidal) and sampling stations (four factors: DAR, MEA, POR and SER) on meiofauna community's structure. Environmental data were previously normalized in \% using the smallest and the largest value in each variable data set, in order to eliminate the units of measurement for data (GraphPad 
Software, Inc.). Heatmaps (basic R heatmap.2 function) were built to assess the log-transformed $(\log (x+1))$ absolute sequence abundance of meiofauna OTUs among sampling units for each marker loci. In order to investigate the relationship between meiofauna OTUs and the main environmental parameters (i.e., salinity, TOM, \% of sandy and muddy fractions), the Canonical Correspondence Analysis (CCA) was performed for each primer pair, testing the significance of constrained inertia by the ANOVA. Lastly, the relative abundance of phyla was determined as cumulative frequency for each station (GraphPad Software, Inc.).

\section{Results}

\subsection{Stage I: Optimisation of protocols}

The Illumina MiSeq high-throughput sequencing generated the following numbers of merged reads: 505,255 (COI-A), 374,109 (COI-B), 571,868 (COI-C), 394,839 (V1-V2), 362,121 (V4) and 505,833 (V9). The following number of representative sequences were produced: 24,144 (COI-A), 73 (COI-B), 91,522 (COI-C), 42,631 (V1-V2), 58,690 (V4) and 20,909 (V9). For the COI-B primer pair, a considerable number of reads of insufficient length $(<50 \mathrm{bp})$ were found and eliminated following alignment against the reference sequences (Tables S5-A). As a consequence, we had not a sufficient number of reads to perform further analyses for this primer pair. For the remaining data, rarefaction curves achieved the saturation (Fig. S2) and the highest number of meiofauna OTUs was recorded using $10.0 \mathrm{~g}$ of sediment (Fig. 1). Namely, for COI-A and V4 primer pairs, up to 1.4 and 1.7 times more OTUs were found respectively in the $10.0 \mathrm{~g}$ of sediment, compared to the next richest sediment amount, while approx. 2 times more OTUs were found in relation to the lowest amount of sediment tested in both primer pairs. However, no significant differences were found among the amounts of sediment used in terms of the number of meiofauna OTUs recorded (two-way ANOVA, $\mathrm{F}=3.3, \mathrm{p}=0.06$ ) or for the interaction between the two factors (two-way ANOVA, $\mathrm{F}=0.5, \mathrm{p}=0.8$ ). On the other hand, the primer pair employed affected significantly the number of recovered meiofauna OTUs (two-way ANOVA, $F=6.5, p=0.003$ ), and globally the highest number of OTUs was recovered with the primer pairs COI-A and V4, for COI and $18 \mathrm{~S}$ marker loci, respectively (Fig. 1).

Qualitatively, a large percentage of OTUs was not assigned to any high taxonomic rank (Fig. S3, Tables S6-A). Among the OTUs attributed to meiofaunal organisms, a higher number of phyla was recorded using COI-A and V4, with 2-4 more phyla than the other primer pairs (Fig. 2). The two marker loci used were somewhat complementary in their ability to recover different phyla: Amoebozoa and Gastrotricha were preferentially detected using COI, while Rotifera and Platyhelminthes preferentially detected with $18 \mathrm{~S}$ (Fig. 2). Additionally, Sipuncula was only detected with COI-C, while Cnidaria and Ciliophora only with V4 and

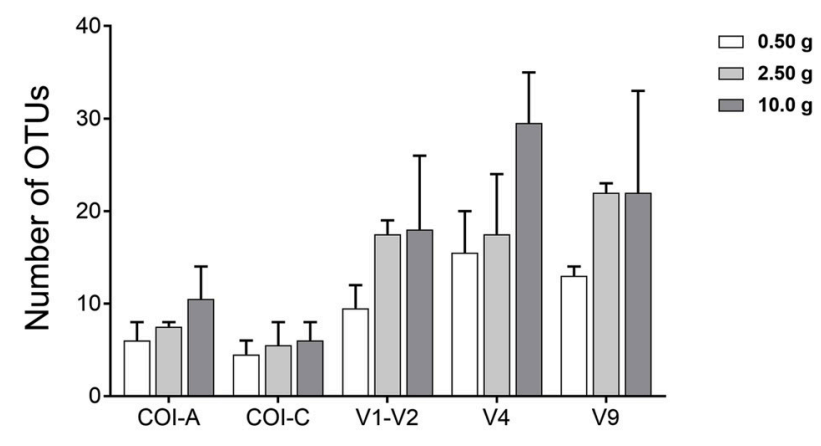

Primer pairs

Fig. 1. Number of OTUs recorded in the Lima estuary for each amount of sediment used for DNA extraction and for each primer pair (average of 2 sampling stations + SEM).
V9 for $18 \mathrm{~S}$ (Fig. 2).

\subsection{Stage II. Spatial variation}

\subsubsection{Rarefaction and accumulation curves}

About half of the initial reads of COI-A and V4 were grouped in OTUs and subsequently taxonomically assigned (Tables S5-B). OTU richness of meiofauna along the four stations in the Lima estuary satisfactorily reached saturation (Fig. S4). The accumulation curves displayed a steep increase of OTU abundance as a function of the sampling effort (Fig. S5). Curves approached saturation at a sampling effort of about 5-6 samples for both marker loci and in each of the four sampling stations (Fig. S5).

\subsubsection{Variation within stations and between intertidal levels}

The spatial structure of meiofauna communities at small-scale was quite pronounced, with an average OTU turnover of approx. 91\% (COIA) and $88 \%$ (V4) between sampling points a few meters apart, within the same intertidal zone in each station (Fig. 3-A). Meiofauna from high intertidal zones and communities targeted with V4 displayed higher OTU turnover, while the lowest values were found at SER station for both marker loci (Fig. 3-A). OTU turnover between intertidal zones ranged approx. from 59 to $83 \%$ and from approx. 63 to $80 \%$ respectively for COI-A and V4, when using the pooled data for 3 sampling points within each zone and station (Fig. 3-B). Among the four sampling stations, the lowest OTU turnover values were recorded within SER for both primer pairs, followed by DAR, POR and MEA (Fig. 3-B).

\subsubsection{Variation between sampling stations}

On average, OTU occurrence overlap was relatively low between the stations for both COI and $18 \mathrm{~S}$, with an average of approx. $11-12 \%$ between each pair of stations, approx. $6-8 \%$ between triplets of stations and only approx. $5-6 \%$ between the four stations (Fig. S6). In particular, the lowest turnover was found between POR/SER for both primer pairs (approx. 85\%), while the highest between DAR/POR for COI-A (approx. 92\%) and between MEA/SER for V4 (approx. 90\%).

For both primer pairs, the OTU richness showed globally low variation and did not differ significantly among stations (two-way ANOVA, $\mathrm{F}=0.04$ and $1.6, \mathrm{p}=1.0$ and 0.2 , for COI-A and V4, respectively; Fig. 4). Although slightly higher values were found in the upper littoral zone of downstream stations and lower in the upstream one, especially at POR (Fig. 4), no significant differences were found in OTUrichness between tidal levels for both primer pairs (two-way ANOVA, $\mathrm{F}=0.2$ and $0.02, \mathrm{p}$ $=0.7$ and 0.9 , for COI-A and $\mathrm{V} 4$, respectively) or for the interaction between both factors (two-way ANOVA, $\mathrm{F}=2.2$ and 3.1, $\mathrm{p}=0.1$ and 0.06 , for COI-A and V4, respectively).

Heatmaps of both marker loci revealed differences in the occurrence of the OTUs among sampling stations and, to a lower extent, between intertidal zones (Fig. 5). No common OTUs were detected in all the 24 sampling points for any of the markers. However, some OTUs had a more widespread occurrence, being recorded in most $(>50 \%)$ of the sampling points. On the other hand, exclusive OTUs were found for particular stations or intertidal levels, hence characterizing and discriminating those locations. The most common OTUs belonged to a diverse set of meiofaunal taxa, including Hexanauplia, Ostracoda, Trombidiformes, Chromadorea, Clitellata, Polychaeta, Proseriata, Rhabditophora, Chaetonotida, Acoela, Eurotatoria (Tables S7 and S8). The exclusive OTUs detected with COI were recorded at each sampling station, including OTUs belonging to the taxa Hexanauplia (DAR), Clitellata, (MEA), Eurotatoria (POR) and Clitellata (SER), while for the $18 \mathrm{~S}$ belonged to Acoela and Gnathostomulita, which were found only in MEA, and Proseriata and Clitellata found in POR (Tables S7 and S8, respectively).

Canonical correspondence analysis (CCA) of the relationships between environmental variables and meiofauna OTUs showed that the first two axes explained approx. $66 \%$ and $67 \%$ of the total variance for COI-A and V4, respectively (Fig. 6). In general, the samples from the 


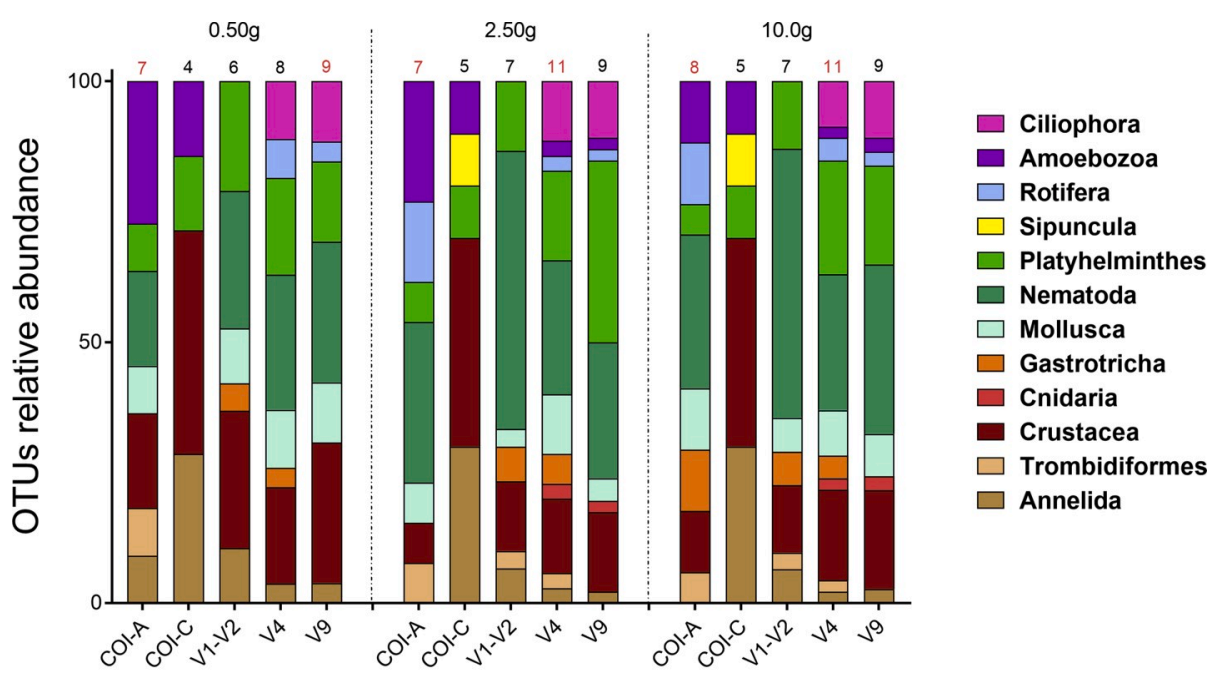

\section{Primer pairs}

Fig. 2. Percentage of OTUs per meiofauna phylum for each of the five primer pairs (COI-A, COI-C, V1-V2, V4, V9) and sediment amount. Numbers at the top of the bars represent the number of phyla found for each primer and sediment amount combination. The phylum Arthropoda was split into Crustacea and Arachnida (Trombidiformes).

A.

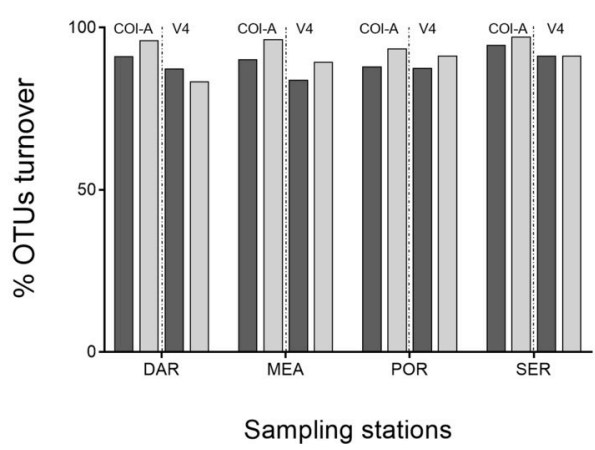

B.

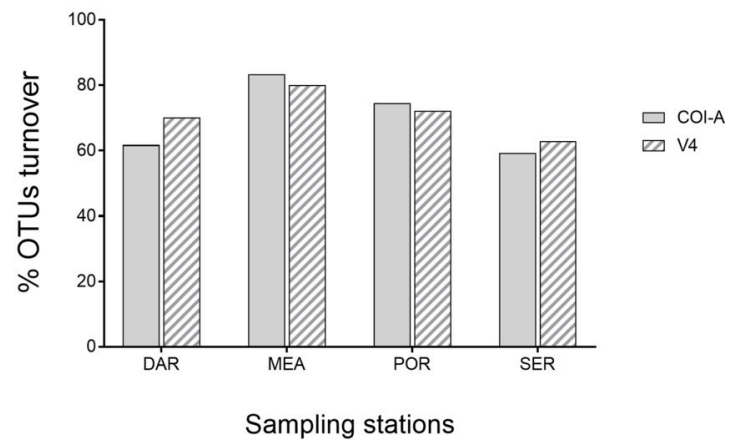

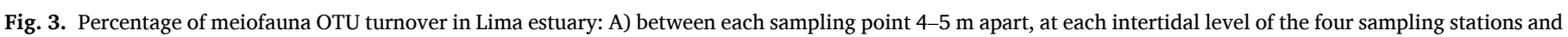
B) between intertidal levels within each station. DAR, Darque; MEA, Meadela; POR, Santa Marta de Portuzelo; SER, Serreleis.

A.

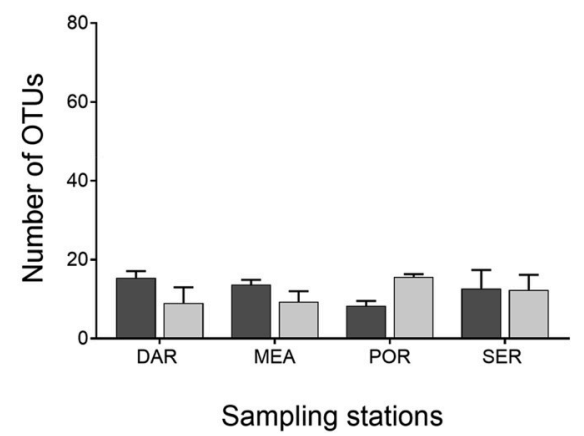

B.

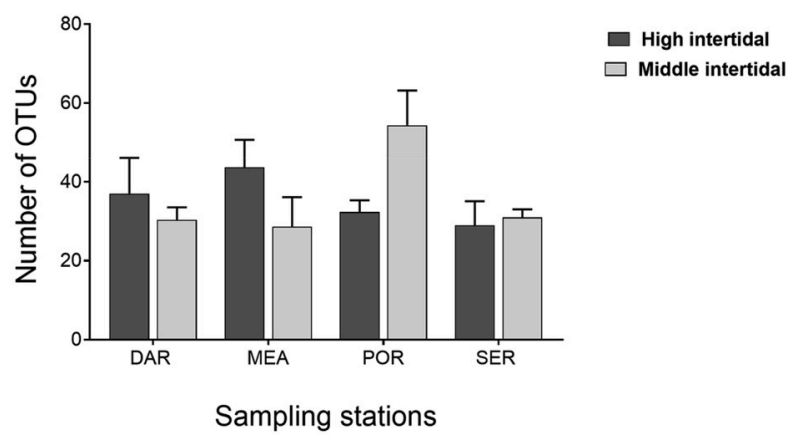

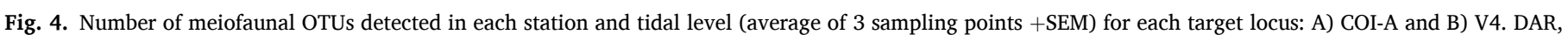
Darque; MEA, Meadela; POR, Santa Marta de Portuzelo; SER, Serreleis. 
A.

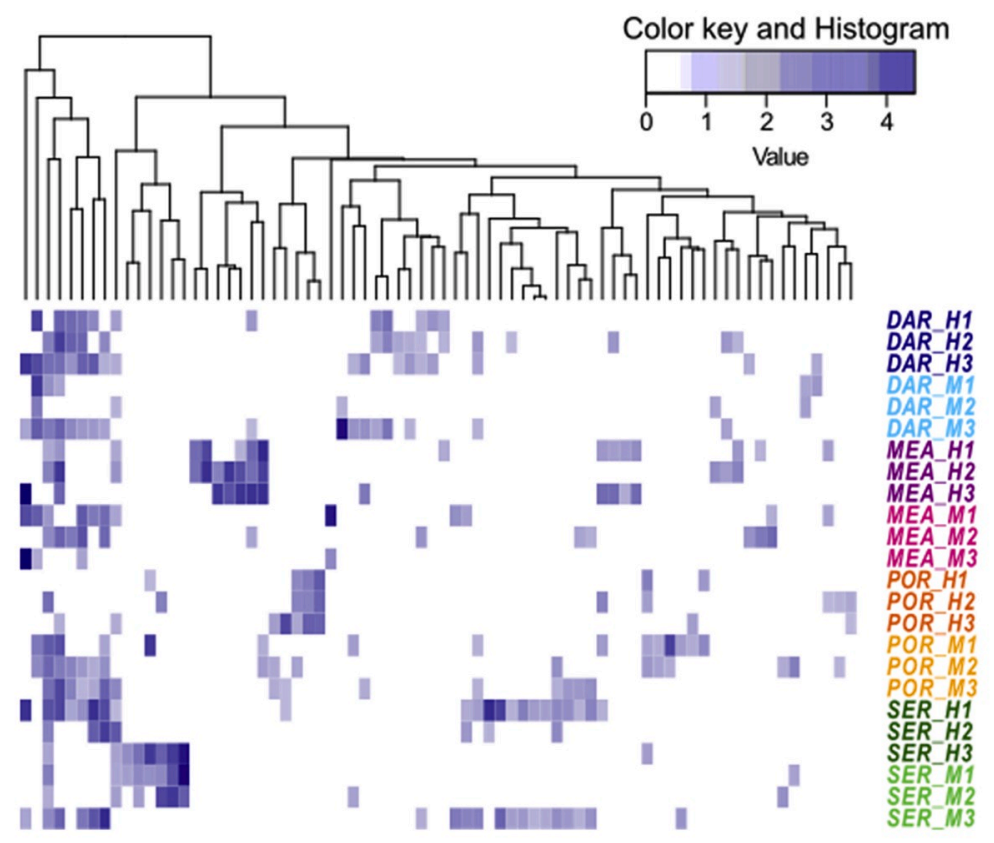

B.

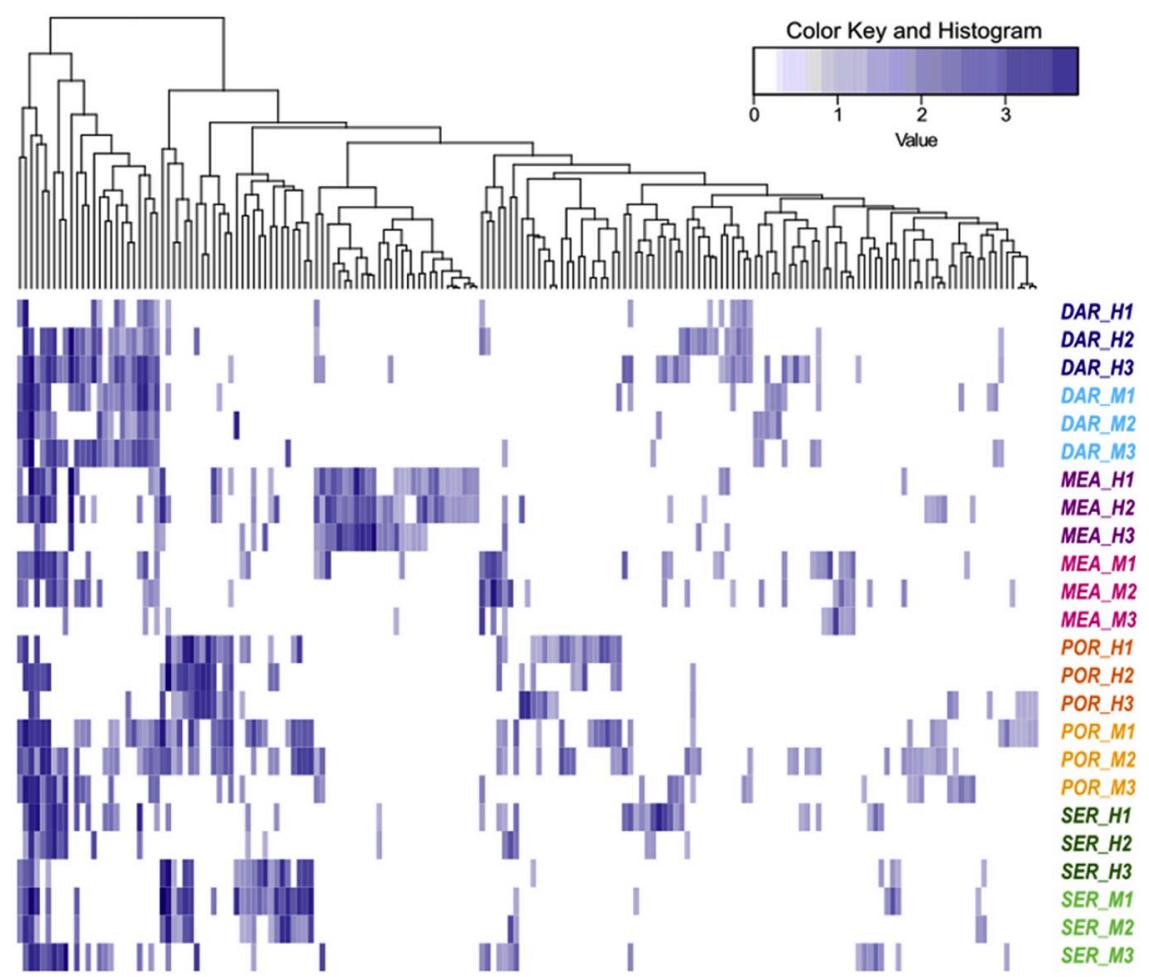

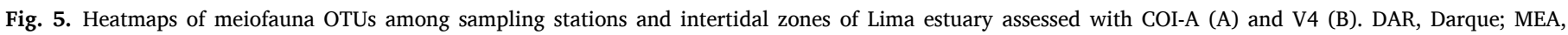
Meadela; POR, Santa Marta de Portuzelo; SER, Serreleis.

same stations grouped together and, in most cases, there was also a clear distinction between tidal levels within the same station for both markers (e.g., POR, DAR and MEA). Results were supported by a non-parametric multivariate analysis of the cluster dendrogram (Fig. S7) that indicated that the sampling station (PERMANOVA, $\mathrm{F}=2.4$ and 2.9, for COI-A and $\mathrm{V} 4$, respectively, $\mathrm{p}=0.001$, for both markers; Table S9) and the interaction between sampling station and tidal level (PERMANOVA, $\mathrm{F}=1.6$ and $\mathrm{p}=0.004$ and $\mathrm{F}=1.8$, and $\mathrm{p}=0.002$, for COI-A and V4, respectively; Table S9) significantly affected meiofauna communities' structure assessed with both markers. Moreover, for V4, the tidal level also affected significantly meiofauna community structure (PERMANOVA, $\mathrm{F}=1.8, \mathrm{p}=0.02$; Table S9). Altogether, environmental variables appeared to influence significantly the structure of meiofauna communities, for both markers (ANOVA, $\mathrm{p}<0.001$, for both markers). In particular, salinity was highly correlated with the second axis for COI-A and with the first axis for V4 (Fig. 6). 
A.

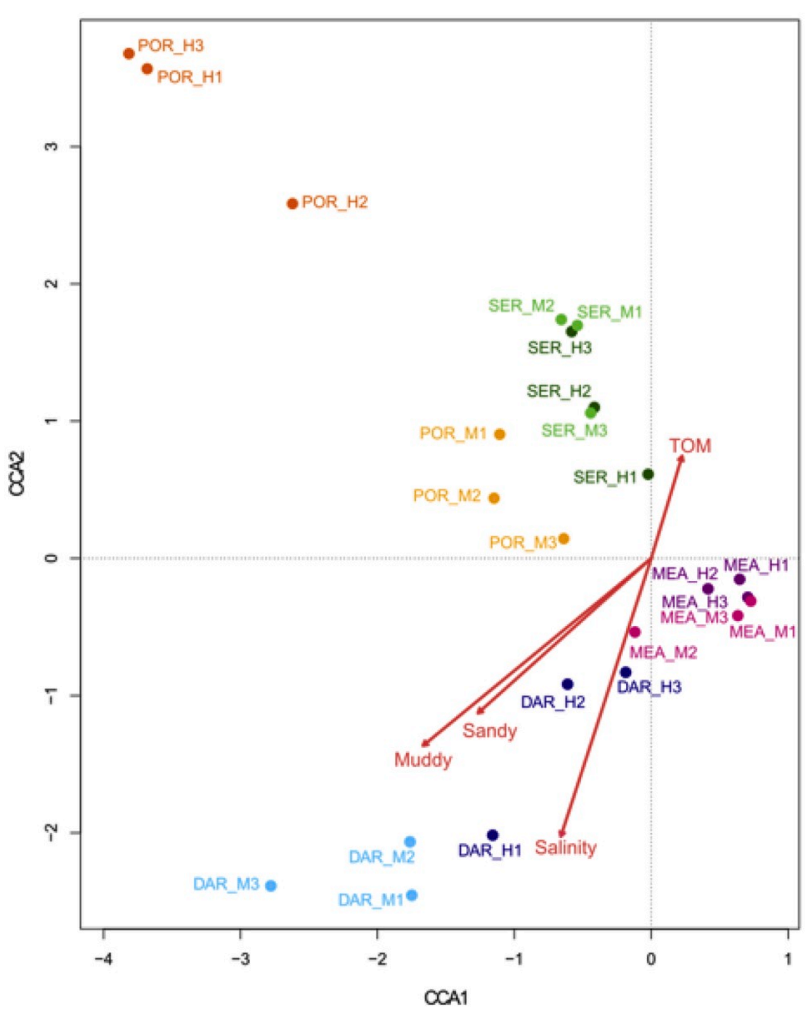

B.

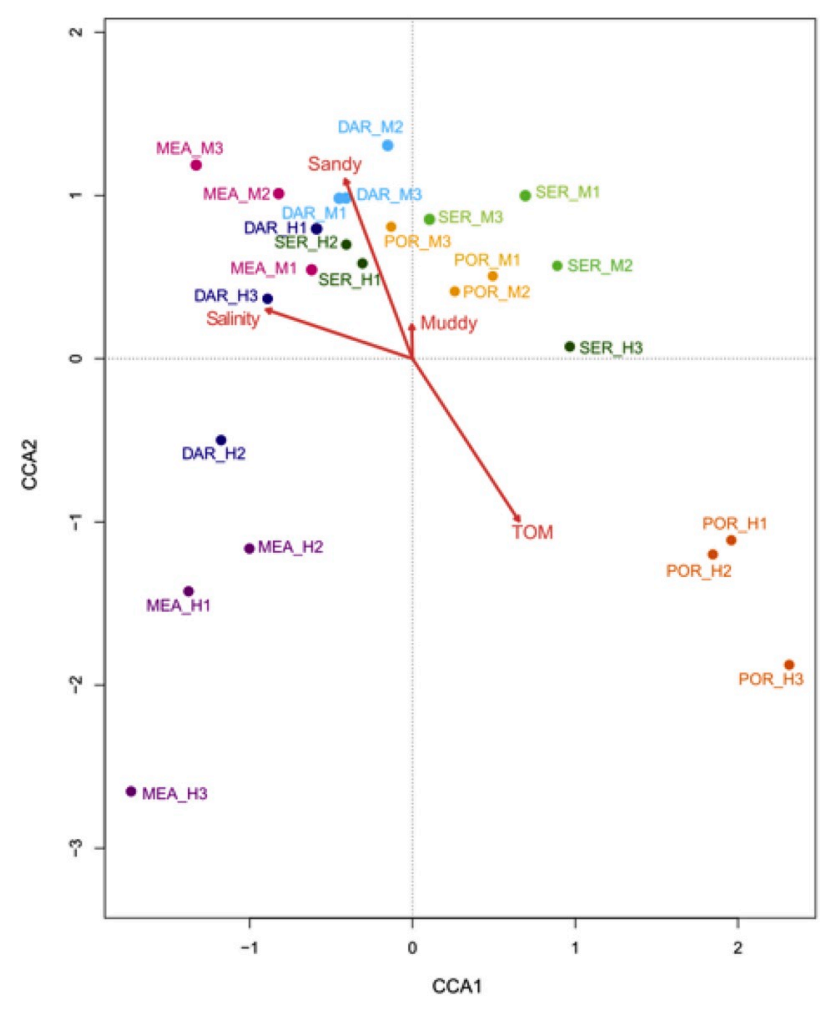

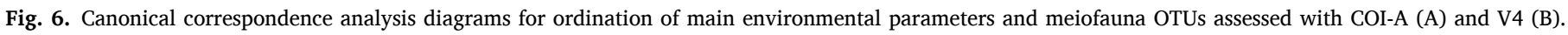

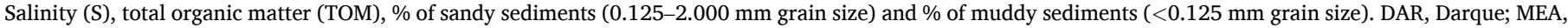
Meadela; POR, Santa Marta de Portuzelo; SER, Serreleis.

As patent in stage I results, a low attribution rate of OTUs was also found in the stage II of the study (Fig. S8, Table S10). The complementarity between the marker loci in the preferential recovery of taxonomic groups was evident both at phyla and class levels (Figs. 7 and S9). OTUs attributions decreased from higher to lower taxonomic ranks (Table S10). Higher taxa were exclusively or preferentially detected by COI-A (Amoebozoa, Cnidaria, Mollusca, Porifera and Rotifera), or by V4 (Ciliophora, Ctenophora, Gnathostomulida, Heliozoa, Platyhelminthes, Xenacoelomorpha; Fig. 7-A). Among the most abundant taxonomic groups for both marker loci, Annelida, Crustacea, Nematoda and Platyhelminthes, in addition to Amoebozoa (for COI-A) and Ciliophora (for V4), were detected (Fig. 7-B). Nematoda and Amoebozoa are the most relevant taxonomic groups for COI-A, while Platyhelminthes, Nematoda and Ciliophora are the most abundant for V4. Results showed a clear difference in the distribution of taxonomic groups among sampling stations. OTUs attributed to Nematoda and to Ciliophora were equally abundant in all the sampling stations, with the exception of SER, when using V4. Amoebozoa (for COI-A), Platyhelminthes, Nematoda and Ciliophora (for V4) presented greater OTUrichness always at POR station.

Nematoda were more abundant at DAR and SER when using COI-A; Annelida were slightly more abundant in MEA for both primer pairs, while Crustacea were somewhat less abundant at POR station with COIA and in DAR with V4. Amoebozoans (COI-A), ciliophorans and Platyhelminthes (V4) increased in the upstream direction (Fig. 7-B).

\section{Discussion}

Currently available molecular technologies offer great promise to improve our understanding of the diversity and dynamics of benthic organisms, therefore enhancing our ability to evaluate less well-known but relevant communities, such as the estuarine meiofauna. Most studies to date applying high throughput sequencing to meiofauna appraisals focus mainly on deep or coastal marine environments and/or their assessment in response to environmental impacts (Creer et al., 2010; Brannock et al., 2014; Fonseca et al., 2014; Guardiola et al., 2015, 2016; Haenel et al., 2017; Nascimento et al., 2018; Cordier et al., 2019). Almost all of these studies use a single molecular marker (generally 18S) and only one primer pair at the time (Creer et al., 2010; Fonseca et al., 2010, 2014; Brannock and Halanych, 2015; Guardiola et al., 2015, 2016; Lejzerowicz et al., 2015; Nascimento et al., 2018). Few of them use both $\mathrm{COI}$ and $18 \mathrm{~S}$ and a selection of multiple primer pairs (Cowart et al., 2015; Haenel et al., 2017; Cordier et al., 2019). Only two studies mentioned above consider the sample size as a weighting component for sampling meiofauna community (Brannock and Halanych, 2015; Nascimento et al., 2018). Comparatively few molecular investigations focus on estuarine or freshwater meiofauna (Chariton et al., 2010; Lallias et al., 2015; Weigand and Macher, 2018) and this study, to our knowledge, is the first assessment of estuarine meiofauna in the Atlantic Lusitanian biogeographic province. In addition, few studies have used a multifactorial approach, in which the sample size, two molecular markers and different sets of primer pairs are screened in order to better understand the small-scale spatial variation of estuarine meiofaunal communities.

\subsection{Stage I: Optimisation of protocols}

Globally, the results indicated that using $10.0 \mathrm{~g}$ of sediment for DNA extraction can have a sizeable influence on the number of meiofaunal OTUs and phyla recorded, and it is most likely to recover more comprehensively the diversity of the community. Although Brannock and Halanych (2015) did not observe meaningfull effects of the amount of sediment on the recovery of marine benthic diversity, other previous studies on soil microbiomes (Ellingsøe et al., 2002; Penton et al., 2016) 
A.

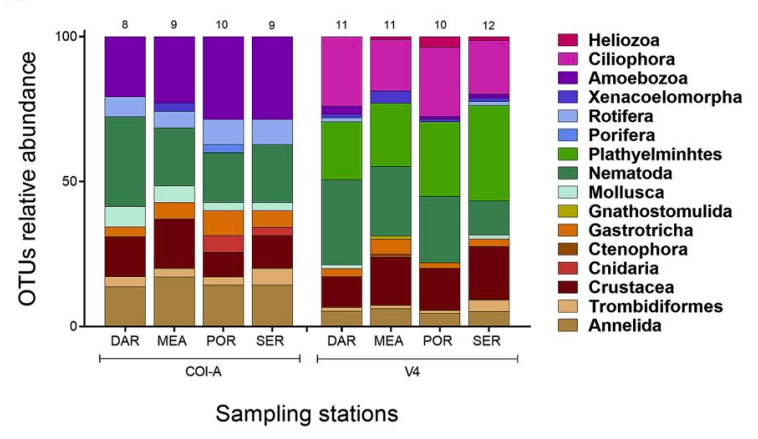

B.

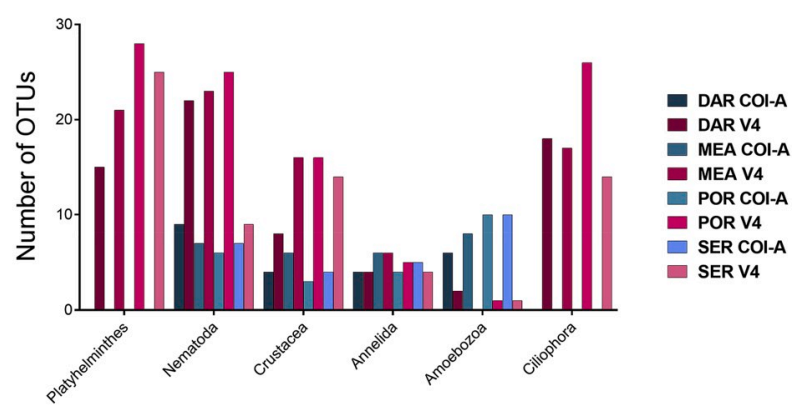

Fig. 7. Relative abundance of phyla attributed to meiofauna taxa (A) and distribution of most abundant phyla (B) detected at the four sampling stations, for each marker loci. Arthropoda were split into Crustacea and Arachnida (Trombidiformes). DAR, Darque; MEA, Meadela; POR, Santa Marta de Portuzelo; SER, Serreleis.

have shown that sample size influences structure and diversity, reporting $10.0 \mathrm{~g}$ of sample as an adequate volume for assessing the communities. Moreover, a recent study on marine meiofauna demonstrated that volumes $\leq 0.20 \mathrm{~g}$ are inefficient for detecting small-scale variation, while $10.0 \mathrm{~g}$ were significantly more suitable to assess the structure of the community (Nascimento et al., 2018). This amount also constitutes a good compromise between a practical amount of sediment to handle, regarding DNA extraction procedures, and a fair assessment of the community's diversity; therefore, it was selected to be used in the second phase of the present study.

Community richness and structure may be also influenced by the target loci and primer pairs employed (Cristescu, 2014; Carugati et al., 2015; Deiner et al., 2015; Sinniger et al., 2016; Haenel et al., 2017; Cristescu and Hebert, 2018). DNA based assessments of meiofauna communities have frequently used various regions of the 18S rRNA gene as a target marker, thanks to its great abundance in the genome, amplification with universal primers, availability of reference libraries, and its use for discerning phylogenetic relationships (Creer et al., 2010; Fonseca et al., 2010; Chariton et al., 2014; Carugati et al., 2015). Nevertheless, $18 \mathrm{~S}$ has limited resolution at lower taxonomic levels (i.e., species) due to its slower rate of evolution compared to COI (Tang et al., 2012; Fontaneto et al., 2015; Lejzerowicz et al., 2015). Moreover, while for COI the reference library usually comprises a single region of $658 \mathrm{bp}$ (COI), the reference library for $18 \mathrm{~S}$ is highly fragmented in most cases, including different combinations of the 9 different hypervariable regions for each taxa, with a not-well defined length across the eukaryotes. Both marker loci also have a gap in the taxa recorded in public reference libraries (Tang et al., 2012; Weigand et al., 2019). To overcome these limitations, the two marker loci have been combined in a number of studies assessing natural communities, including meiofauna (Cowart et al., 2015; Leasi et al., 2016; Haenel et al., 2017; Cristescu and Hebert, 2018; Grey et al., 2018; Wangensteen et al., 2018).

The fair proportions of unassigned OTUs obtained with both COI and
$18 \mathrm{~S}$ are likely a result of significant gaps in meiofauna taxa deposited in the nucleotide database used in the present study (i.e., GenBank). Hence, either disparites in taxonomic representativeness in reference libraries and/or primer bias, may have contributed to some level of complementarity between the two markers employed (COI or 18S) in the taxonomic breadth of recorded OTUs. For instance, Amoebozoa and Porifera were preferentially or exclusively detected with COI, while Ciliophora and Platyhelminthes with $18 \mathrm{~S}$. Thence, if the goal is to characterize as best as possible the communities, $18 \mathrm{~S}$ and COI should be used together in DNA metabarcoding studies on meiofauna assemblages, as suggested by previous investigations (Cowart et al., 2015; Leasi et al., 2016; Cristescu and Hebert, 2018; Grey et al., 2018) and reinforced by the present study. Nevertheless, not all the primer pairs within a marker locus have the same detection performance (Hadziavdic et al., 2014; Haenel et al., 2017; Hollatz et al., 2017; Lobo et al., 2017). In the present study, the COI-A (for the COI sub-region) and the V4 (for the 18S rRNA gene) primers were the ones with a better performance in terms of OTUs recovered and taxonomic diversity of meiofauna, and were consequently selected for the stage II of the study. Two of the 18S rRNA gene primers (V4 and V9) did not differ much in number of OTUs recovered, but globally V4 captured a slightly higher number of phyla.

\subsection{Stage II: Spatial variation}

The achievement of saturation in the accumulation curves is an important criterion in environmental monitoring, allowing to design an optimal sampling effort for the studied community (Thompson and Withers, 2003; Thompson et al., 2003, 2007). Accumulation curves in this study were asymptotic for both primer pairs, suggesting that the sampling effort applied was adequate to inventory the meiofauna diversity in Lima estuary, with 5-6 sampling points per sampling station determined as the minimum required to reach saturation.

OTU turnover was fairly high among sampling points within each station, particularly if we consider that they were only a few meters apart. This pattern of high OTU turnover at a small scale was consistently observed for both target loci and in all sampling stations. High spatial variation in estuarine meiofauna communities has already been recorded both through classical biomonitoring studies and metabarcoding (viz. Alves et al., 2009; Lallias et al., 2015; Sun et al., 2017). The present study not only does confirm the patchy distribution of meiofauna, but emphasizes this relevant observation at a narrow spatial scale (i.e., between sampling points a few meters apart, and between the high and the middle intertidal zone), and warn for its consequences for estuarine meiofaunal surveys and ecological status assessment. Considering these findings together with the results of the accumulation curves, in order to capture more accurately the composition of the meiofaunal communities in estuarine ecosystems, it would be appropriate to apply a clustering sampling approach (Wang et al., 2012), with a minimum of 6 sampling points within a station, covering different levels of the intertidal zone.

Results indicated that the meiofauna OTU richness recovered is more variable among stations when targeted with $18 \mathrm{~S}$ compared to COI. This difference reinforces the motivation to use more than one marker locus when assessing meiobenthic communities through DNA metabarcoding, as discussed above. Regardless of the primer pair used, the occurrence of particular OTUs varies along the four sampled stations, with highly frequent, moderately frequent and rare OTUs being differently recorded, as expected (Sun et al., 2017 and references therein). OTU occurrence and heatmaps showed more incidence of frequent OTUs in the most upstream station (SER), moderately frequent OTUs in the most downstream (DAR) and in the POR stations, and rare OTUs at MEA station. The presence of most common OTUs at SER would support the hypothesis of more stable environmental conditions. On the other hand, intermediate and rare OTUs could indicate the presence of more opportunistic species, able to eventually become more abundant depending on the environmental changes, as demonstrated in previous 
studies (viz., Sun et al. and references therein). Moreover, meiofauna community of Lima estuary is generally grouped by sampling stations, with some local assemblages determined by key environmental factors. Indeed, from the analysis on CCAs, the relevance of salinity in shaping small-scale meiofauna variation emerged from the other environmental features considered. However, CCAs were able to explain about $67 \%$ of variance for both marker loci used, meaning that other factors not considered in this study (e.g., oxygenation in the interstitial space; nutrients; trophic interaction between meiofauna and microbiome and/or macrobenthos) may have additional influence in the meiofauna community's structure of Lima estuary. Several studies have shown how salinity fluctuations are determinant for spatial sorting of estuarine meiofauna assemblages (Alves et al., 2009 and references therein; Lallias et al., 2015; Sun et al., 2017). However, different studies emphasize that other abiotic and biological factors (e.g., sediment grain size, availability of organic matter, predation, competition, reproductive strategies, etc.) contribute to characterize the patchy distribution patterns of this community (Alves et al., 2009 and references therein; Faria et al., 2018).

From a taxonomic point of view, both morphology (Warwick and Gee, 1984; Alves et al., 2009) and DNA-based approaches (Fonseca et al., 2010, 2014; Lallias et al., 2015; Faria et al., 2018) have been recording nematodes as one of the most dominant groups of meiobenthic communities, especially in fine sediments. This research confirmed their dominance across the sampling stations, together with other emerging groups (platyhelminths, crustaceans, annelids, ciliophorans and amoebozoans). As expected, considering the main groups of these representative phyla, Chromadorea (Nematoda) were more abundant at higher salinity, while Rhabdocoela (Platyhelminthes) at lower salinity. The same complementarity was found in Polychaeta vs. Clitellata (within Annelida) and in Hexanauplia vs. Ostracoda (Arthropoda, Crustacea). Within meiofauna protists, Discosea and Spirotrichea were higher at the upstream stations.

\section{Conclusion}

On one hand, this study showed how the sample's size (i.e., amount of sediment), the choice of marker loci and primer pairs, and the sampling's spatial design may influence the assessment of the diversity and taxonomic composition of estuarine meiobenthic communities. On the other hand, it emphasizes variation of the composition of the meiofauna at a short distance (i.e., 4-5 m apart). This highly patchy distribution of meiofauna recorded in Lima estuary probably reflects the presence of numerous microhabitats generated by small-scale changes in environmental factors, resulting in the development of very localized communities. The presence of station specific and low-frequency OTUs in the micro-eukaryotic communities, as well as the high OTU turnover at small spatial scale suggests the need to re-appreciate the common perception of the trend for somewhat widespread and uniform occurrence of meiofauna taxa. Further investigation must be performed using comprehensive spatial and time scales to deepen our understanding of the distribution and occurrence patterns of the estuarine meiofauna, in Lima estuary and other nearby coastal ecosystems of the Atlantic Lusitanian biogeographic province.

\section{Declaration of competing interest}

The authors declare that they have no known competing financial interests or personal relationships that could have appeared to influence the work reported in this paper.

\section{CRediT authorship contribution statement}

Maria Fais: Conceptualization, Methodology, Software, Validation, Formal analysis, Investigation, Data curation, Writing - original draft, Writing - review \& editing, Visualization. Sofia Duarte:
Conceptualization, Methodology, Formal analysis, Investigation, Resources, Writing - original draft, Writing - review \& editing, Visualization. Pedro Emanuel Vieira: Conceptualization, Validation, Formal analysis, Writing - review \& editing, Visualization, Visualization. Ronaldo Sousa: Writing - review \& editing, Visualization, Supervision. Mehrdad Hajibabaei: Writing - review \& editing, Visualization, Supervision. Carlos Alberto Canchaya: Conceptualization, Methodology, Software, Validation, Formal analysis, Data curation, Writing - review \& editing, Visualization, Supervision. Filipe Oliveira Costa: Conceptualization, Methodology, Validation, Resources, Writing - original draft, Writing - review \& editing, Visualization, Supervision, Project administration, Funding acquisition.

\section{Acknowledgements}

This study was funded by the project "The NextSea: Next generation monitoring of coastal ecosystems in a scenario of global change" (operação NORTE-01-0145-FEDER-000032), supported by Norte Portugal Regional Operational Programme (NORTE 2020), under the PORTUGAL 2020 Partnership Agreement, through the European Regional Development Fund (ERDF). Maria Fais and Sofia Duarte were supported, respectively by a $\mathrm{PhD}(\mathrm{SFRH} / \mathrm{BD} / 113547 / 2015)$ and a postdoc fellowship (SFRH/BPD/109842/2015) from FCT. The authors would like to thank Prof. Jesús Troncoso (University of Vigo) and Prof. Pedro Gomes (University of Minho) for their availability and hospitality for the lab processing, as well as Barbara Leite (University of Minho) and Manuel Mendoza (University of Vigo) for their help during the sampling and data analysis phases, respectively.

\section{Appendix A. Supplementary data}

Supplementary data to this article can be found online at https://doi. org/10.1016/j.ecss.2020.106683.

\section{References}

Alves, A.S., Adão, H., Patrício, J., Neto, J.M., Costa, M.J., Marques, J.C., 2009. Spatial distribution of subtidal meiobenthos along estuarine gradients in two southern European estuaries (Portugal). Acta Oecol. 35, 287-300. https://doi.org/10.1016/j. actao.2008.11.007.

Baas-Becking, L.G.M., 1934. Geobiologie of inleiding tot de milieukunde. Den Haag: W.P. van Stockum and Zoon, p. 263. https://doi.org/10.1007/s10825-011-0356-9.

Benson, D.A., Cavanaugh, M., Clark, K., Karsch-Mizrachi, I., Ostell, J., Pruitt, K.D., Sayers, E.W., 2018. GenBank. Nucleic Acids Res. 46, D41-D47. https://doi.org/ 10.1093/nar/gkx1094.

Brannock, P.M., Halanych, K.M., 2015. Meiofaunal community analysis by highthroughput sequencing: comparison of extraction, quality filtering, and clustering methods. Mar. Genomics 23, 67-75. https://doi.org/10.1016/j. margen.2015.05.007.

Brannock, P.M., Waits, D.S., Sharma, J., Halanych, K.M., 2014. High-throughput sequencing characterizes intertidal meiofaunal communities in northern Gulf of Mexico (Dauphin island and mobile bay, Alabama). Biol. Bull. 227, 161-174. https://doi.org/10.1086/BBLv227n2p161.

Carugati, L., Corinaldesi, C., Dell'Anno, A., Danovaro, R., 2015. Metagenetic tools for the census of marine meiofaunal biodiversity: an overview. Mar. Genomics 24, 11-20. https://doi.org/10.1016/j.margen.2015.04.010.

Chariton, A.A., Court, L.N., Hartley, D.M., Colloff, M.J., Hardy, C.M., 2010. Ecological assessment of estuarine sediments by pyrosequencing eukaryotic ribosomal DNA. Front. Ecol. Environ. 8, 233-238. https://doi.org/10.1890/090115.

Chariton, A.A., Ho, K.T., Proestou, D., Bik, H., Simpson, S.L., Portis, L.M., Cantwell, M.G., Baguley, J.G., Burgess, R.M., Pelletier, M.M., Perron, M., Gunsch, C., Matthews, R.A., 2014. A molecular-based approach for examining responses of eukaryotes in microcosms to contaminant-spiked estuarine sediments. Environ. Toxicol. Chem. 33, 359-369, https://doi.org/10,1002/etc. 2450.

Clare, E.L., Chain, F.J.J., Littlefair, J.E., Cristescu, M.E., Deiner, K., 2016. The effects of parameter choice on defining molecular operational taxonomic units and resulting ecological analyses of metabarcoding data 1 . Genome 59, 981-990. https://doi.org/ 10.1139/gen-2015-0184.

Coissac, E., Riaz, T., Puillandre, N., 2012. Bioinformatic challenges for DNA metabarcoding of plants and animals. Mol. Ecol. 21, 1834-1847. https://doi.org/ 10.1111/j.1365-294X.2012.05550.x.

Cordier, T., Frontalini, F., Cermakova, K., Apothéloz-Perret-Gentil, L., Treglia, M., Scantamburlo, E., Bonamin, V., Pawlowski, J., 2019. Multi-marker eDNA metabarcoding survey to assess the environmental impact of three offshore gas 
platforms in the North Adriatic Sea (Italy). Mar. Environ. Res. 146, 24-34. https:/ doi.org/10.1016/j.marenvres.2018.12.009.

Coull, B.C., 1999. Role of meiofauna in estuarine soft-bottom habitats. Aust. J. Ecol. 24, 327-343. https://doi.org/10.1046/j.1442-9993.1999.00979.x.

Coull, B.C., Chandler, G.T., 2019. Meiobenthos. In: Cochran, J.K., Bokuniewicz, H.J., Yager, P.L. (Eds.), Encyclopedia of Ocean Science, vol. 1. Elselvier Ltd, ISBN 978-012-813081-0, pp. 742-748. Marine Biogeochemistry.

Cowart, D.A., Pinheiro, M., Mouchel, O., Maguer, M., Grall, J., Miné, J., ArnaudHaond, S., 2015. Metabarcoding is powerful yet still blind: a comparative analysis of morphological and molecular surveys of seagrass communities. PloS One 10, 1-26. https://doi.org/10.1371/journal.pone.0117562.

Creer, S., Fonseca, V.G., Porazinska, D.L., Giblin-Davis, R.M., Sung, W., Power, D.M., Packer, M., Carvalho, G.R., Blaxter, M.L., Lambshead, P.J.D., Thomas, W.K., 2010 Ultrasequencing of the meiofaunal biosphere: practice, pitfalls and promises. Mol. Ecol. 19, 4-20. https://doi.org/10.1111/j.1365-294X.2009.04473.x.

Creer, S., Deiner, K., Frey, S., Porazinska, D., Taberlet, P., Thomas, W.K., Potter, C., Bik, H.M., 2016. The ecologist's field guide to sequence-based identification of biodiversity. Methods Ecol. Evol. 7, 1008-1018. https://doi.org/10.1111/2041210X.12574.

Cristescu, M.E., 2014. From barcoding single individuals to metabarcoding biological communities: towards an integrative approach to the study of global biodiversity. Trends Ecol. Evol. 29 (10), 566-571. https://doi.org/10.1016/j.tree.2014.08.001.

Cristescu, M.E., Hebert, P.D.N., 2018. Uses and misuses of environmental DNA in biodiversity science and conservation. Annu. Rev. Ecol. Evol. Syst. 49, 209-230. https://doi.org/10.1146/annurev-ecolsys-110617-062306.

Day, J.W., Crump, B.C., Kemp, W.M., Yáñez-Arancibia, A., 2012. Estuarine Ecology, Estuarine Ecology. Wiley-Blackwell, New Jersey, p. 554. https://doi.org/10.1002/ 9781118412787.

Deiner, K., Walser, J.C., Mächler, E., Altermatt, F., 2015. Choice of capture and extraction methods affect detection of freshwater biodiversity from environmental DNA. Biol. Conserv. 183, 53-63. https://doi.org/10.1016/j.biocon.2014.11.018.

Edgar, R.C., Flyvbjerg, H., 2018. Alpha Diversity Metrics for Noisy OTUs. https://doi. org/10.1101/434977.

Ellingsøe, P., Johnsen, K., 2002. Influence of soil sample sizes on the assessment of bacterial community structure. Soil Biol. Biochem. 34, 1701-1707. https://doi.org/ 10.1016/S0038-0717(02)00156-6Chandke.

Faria, L.C. de, Di Domenico, M., Andrade, S.C.S., Santos, M.C. dos, Fonseca, G., Zanol, J., Amaral, A.C.Z., 2018. The use of metabarcoding for meiofauna ecological patterns assessment. Mar. Environ. Res. 140, 160-168. https://doi.org/10.1016/j. marenvres.2018.06.013.

Ficetola, G.F., Pansu, J., Bonin, A., Coissac, E., Giguet-Covex, C., De Barba, M., Gielly, L. Lopes, C.M., Boyer, F., Pompanon, F., Rayé, G., Taberlet, P., 2015. Replication levels, false presences and the estimation of the presence/absence from eDNA metabarcoding data. Mol. Ecol. Resour. 15, 543-556. https://doi.org/10.1111/ 1755-0998.12338.

Ficetola, G., Taberlet, P., Coissac, E., 2016. How to limit false positives in environmental DNA and metabarcoding? Mol. Ecol. Resour. 16, 604-607. https://doi.org/10.1111/ 1755-0998.12508.

Flynn, J.M., Brown, E.A., Chain, F.J.J., Macisaac, H.J., Cristescu, M.E., 2015. Toward accurate molecular identification of species in complex environmental samples: testing the performance of sequence filtering and clustering methods. Ecol. Evol. 5, 2252-2266. https://doi.org/10.1002/ece3.1497.

Fonseca, V.G., Carvalho, G.R., Sung, W., Johnson, H.F., Power, D.M., Neill, S.P., Packer, M., Blaxter, M.L., Lambshead, P.J.D., Thomas, W.K., Creer, S., 2010. Secondgeneration environmental sequencing unmasks marine metazoan biodiversity. Nat. Commun. 1, 1-8. https://doi.org/10.1038/ncomms1095.

Fonseca, V.G., Carvalho, G.R., Nichols, B., Quince, C., Johnson, H.F., Neill, S.P., Lambshead, J.D., Thomas, W.K., Power, D.M., Creer, S., 2014. Metagenetic analysi of patterns of distribution and diversity of marine meiobenthic eukaryotes. Global Ecol. Biogeogr. 23, 1293-1302. https://doi.org/10.1111/geb.12223.

Fontaneto, D., 2011. Biogeography of Microscopic Organisms: Is Everything Small Everywhere? Cambridge University Press, New York, p. 388. https://doi.org/ 10.1017/CBO9780511974878.

Fontaneto, D., Flot, J.F., Tang, C.Q., 2015. Guidelines for DNA taxonomy, with a focus on the meiofauna. Mar. Biodivers. 45, 433-451. https://doi.org/10.1007/s12526-0150319-7.

Gibson, J., Shokralla, S., Porter, T.M., King, I., van Konynenburg, S., Janzen, D.H., Hallwachs, W., Hajibabaei, M., 2014. Simultaneous assessment of the macrobiome and microbiome in a bulk sample of tropical arthropods through DNA metasystematics. Proc. Natl. Acad. Sci. Unit. States Am. 111, 8007-8012. https:// doi.org/10.1073/pnas.1406468111.

Giere, O., 2009. Meiobenthology: the Microscopic Motile Fauna of Aquatic Sediments. Springer, Berlin, p. 527. https://doi.org/10.1007/978-3-540-68661-3.

Goldberg, C.S., Turner, C.R., Deiner, K., Klymus, K.E., Thomsen, P.F., Murphy, M.A., Spear, S.F., McKee, A., Oyler-McCance, S.J., Cornman, R.S., Laramie, M.B., Mahon, A.R., Lance, R.F., Pilliod, D.S., Strickler, K.M., Waits, L.P., Fremier, A.K., Takahara, T., Herder, J.E., Taberlet, P., 2016. Critical considerations for the application of environmental DNA methods to detect aquatic species. Methods Ecol. Evol. 7, 1299-1307. https://doi.org/10.1111/2041-210X.12595.

Grey, E.K., Bernatchez, L., Cassey, P., Deiner, K., Deveney, M., Howland, K.L., Lacoursière-Roussel, A., Leong, S.C.Y., Li, Y., Olds, B., Pfrender, M.E., Prowse, T.A A., Renshaw, M.A., Lodge, D.M., 2018. Effects of sampling effort on biodiversity patterns estimated from environmental DNA metabarcoding surveys. Sci. Rep. 8, 8843. https://doi.org/10.1038/s41598-018-27048-2.

Guardiola, M., Uriz, M.J., Taberlet, P., Coissac, E., Wangensteen, O.S., Turon, X., 2015 Deep-Sea, deep-sequencing: metabarcoding extracellular DNA from sediments of marine canyons. PloS One 10, e0139633. https://doi.org/10.1371/journal. pone. 0139633

Guardiola, M., Wangensteen, O.S., Taberlet, P., Coissac, E., Uriz, M.J., Turon, X., 2016. Spatio-temporal monitoring of deep-sea communities using metabarcoding of sediment DNA and RNA. PeerJ 4, e2807. https://doi.org/10.7717/peerj.2807.

Hadziavdic, K., Lekang, K., Lanzen, A., Jonassen, I., Thompson, E.M., Troedsson, C. 2014. Characterization of the 18s rRNA gene for designing universal eukaryote specific primers. PloS One 9 (2), e87624. https://doi.org/10.1371/journal. pone.0087624.

Haenel, Q., Holovachov, O., Jondelius, U., Sundberg, P., Bourlat, S., 2017. NGS-based biodiversity and community structure analysis of meiofaunal eukaryotes in shell sand from Hållö island, Smögen, and soft mud from Gullmarn Fjord, Sweden. Biodivers. Data J. 5, e12731 https://doi.org/10.3897/BDJ.5.e12731.

Hardy, C.M., Krull, E.S., Hartley, D.M., Oliver, R., 2010. Carbon source accounting for fish using combined DNA and stable isotope analyses in a regulated lowland river weir pool. Mol. Ecol. 19 (1), 197-212. https://10.1111/j.1365-294X.2009.04411.x.

Higgins, R.P., Thiel, H., 1988. Introduction to the Study of Meiofauna. Smithsonian Institution Press, Washington D.C, ISBN 0-87474-488-1, p. 488.

Hollatz, C., Leite, B.R., Lobo, J., Froufe, H., Egas, C., Costa, F.O., 2017. Priming of a DNA metabarcoding approach for species identification and inventory in marine macrobenthic communities. Genome 60, 260-271. https://doi.org/10.1139/gen 2015-0220.

Huson, D.H., Beier, S., Flade, I., Górska, A., El-Hadidi, M., Mitra, S., Ruscheweyh, H.J., Tappu, R., 2016. MEGAN community edition - interactive exploration and analysis of large-scale microbiome sequencing data. PLoS Comput. Biol. 12 (6), e1004957 https://doi.org/10.1371/journal.pcbi.1004957.

Kozich, J.J., Westcott, S.L., Baxter, N.T., Highlander, S.K., Schloss, P.D., 2013. Development of a dual-index sequencing strategy and curation pipeline for analyzing amplicon sequence data on the miseq illumina sequencing platform. Appl. Environ. Microbiol. 79, 5112-5120. https://doi.org/10.1128/AEM.01043-13.

Lallias, D., Hiddink, J.G., Fonseca, V.G., Gaspar, J.M., Sung, W., Neill, S.P., Barnes, N., Ferrero, T., Hall, N., Lambshead, P.J.D., Packer, M., Thomas, W.K., Creer, S., 2015. Environmental metabarcoding reveals heterogeneous drivers of microbial eukaryote diversity in contrasting estuarine ecosystems. ISME J. 9 (5), 1208-1221. https://doi. org/10.1038/ismej.2014.213.

Leasi, F., Andrade, S.C.D.S., Norenburg, J., 2016. At least some meiofaunal species are not everywhere. Indication of geographic, ecological and geological barriers affecting the dispersion of species of Ototyphlonemertes (Nemertea, Hoplonemertea). Mol. Ecol. 25, 1381-1397. https://doi.org/10.1111/mec.13568.

Leasi, F., Sevigny, J.L., Laflamme, E.M., Artois, T., Curini-Galletti, M., de Jesus Navarrete, A., Di Domenico, M., Goetz, F., Hall, J.A., Hochberg, R., Jörger, K.M., Jondelius, U., Todaro, M.A., Wirshing, H.H., Norenburg, J.L., Thomas, W.K., 2018. Biodiversity estimates and ecological interpretations of meiofaunal communities are biased by the taxonomic approach. Commun. Biol 1, 1-10. https://doi.org/10.1038/ s42003-018-0119-2, 112.

Lejzerowicz, F., Esling, P., Pillet, L., Wilding, T.A., 2015. High-throughput sequencing and morphology perform equally well for benthic monitoring of marine ecosystems. Sci. Rep. 5, 13932. https://doi.org/10.1038/srep13932.

Leray, M., Knowlton, N., 2017. Random sampling causes the low reproducibility of rare eukaryotic OTUs in Illumina COI metabarcoding Peer. PeerJ 5, e3006. https://doi. org/10.7717/peerj.3006.

Leray, M., Yang, J.Y., Meyer, C.P., Mills, S.C., Agudelo, N., Ranwez, V., Boehm, J.T., Machida, R.J., 2013. A new versatile primer set targeting a short fragment of the mitochondrial COI region for metabarcoding metazoan diversity: application for characterizing coral reef fish gut contents. Front. Zool. 10 (34), 1-14. https://doi. org/10.1186/1742-9994-10-34.

Lobo, J., Costa, P.M., Teixeira, M.A.L., Ferreira, M.S.G., Costa, M.H., Costa, F.O., 2013. Enhanced primers for amplification of DNA barcodes from a broad range of marine metazoans. BMC Ecol. 13, 1. https://doi.org/10.1186/1472-6785-13-34.

Lobo, J., Shokralla, S., Costa, M.H., Hajibabaei, M., Costa, F.O., 2017. DNA metabarcoding for high-throughput monitoring of estuarine macrobenthic communities. Sci. Rep. 7, 15618. https://doi.org/10.1038/s41598-017-15823-6.

Majaneva, M., Hyytiäinen, K., Varvio, S.L., Nagai, S., Blomster, J., 2015. Bioinformatic amplicon read processing strategies strongly affect eukaryotic diversity and the taxonomic composition of communities. Plos One 10 (6), e0130035.

Mare, M.F., 1942. A study of a marine benthic community with special reference to the micro-organisms. JMBA (J. Mar. Biol. Assoc.) 25 (3), 517-554. https://doi.org/ 10.1017/S0025315400055132.

McIntyre, A.D., 1969. Ecology of marine meiobenthos. Biol. Rev. 44, 245-288. https:// doi.org/10.1111/j.1469-185X.1969.tb00828.x.

McMurdie, P.J., Holmes, S., 2014. Waste not, want not: why rarefying microbiome data is inadmissible. PLoS Comput. Biol. 10 (4), e1003531 https://doi.org/10.1371/ journal.pcbi.1003531.

Nascimento, F.J.A., Lallias, D., Bik, H.M., Creer, S., 2018. Sample size effects on the assessment of eukaryotic diversity and community structure in aquatic sediments using high-throughput sequencing. Sci. Rep. 8, 11737. https://doi.org/10.1038/ s41598-018-30179-1.

Oksanen, J., Blanchet, F.G., Kindt, R., Legendre, P., Minchin, P.R., O'Hara, R.B., Simpson, G.L., Solymos, P., Stevens, M.H.H., Wagner, H., 2013. Package 'vegan'. R Packag. https://doi.org/10.4135/9781412971874.n145 ver. 2.5-2.

O'Malley, M.A., 2008. 'Everything is everywhere: but the environment selects': ubiquitous distribution and ecological determinism in microbial biogeography. Stud. Hist. Philos. Sci. Part C Stud. Hist. Philos. Biol. 39 (3), 314-325. https://doi.org/ 10.1016/j.shpsc.2008.06.005.

Penton, C.R., Gupta, V.V.S.R., Yu, J., Tiedje, J.M., 2016. Size matters: assessing optimum soil sample size for fungal and bacterial community structure analyses using high 
throughput sequencing of rRNA gene amplicons. Front. Microbiol. 7, 824. https:// doi.org/10.3389/fmicb.2016.00824.

Por, F.D., 1972. Hydrobiological notes on the high-salinity waters of the Sinai Peninsula. Mar. Biol. 14 (2), 111-119. https://doi.org/10.1007/BF00373210.

Rognes, T., Flouri, T., Nichols, B., Quince, C., Mahé, F., 2016. VSEARCH: a versatile open source tool for metagenomics. PeerJ 4, e2584. https://doi.org/10.7717/peerj.2584.

RStudio Team, 2018. RStudio. Integrated Development for R. RStudio, Inc., Boston, MA. URL. http://www.rstudio.com.

Savage, C., Thrush, S.F., Lohrer, A.M., Hewitt, J.E., 2012. Ecosystem services transcend boundaries: estuaries provide resource subsidies and influence functional diversity in coastal benthic communities. PloS One 7 (8), e42708. https://doi.org/10.1371/ journal.pone. 0042708 .

Schloss, P.D., Westcott, S.L., Ryabin, T., Hall, J.R., Hartmann, M., Hollister, E.B. Lesniewski, R.A., Oakley, B.B., Parks, D.H., Robinson, C.J., Sahl, J.W., Stres, B., Thallinger, G.G., Van Horn, D.J., Weber, C.F., 2009. Introducing mothur: opensource, platform-independent, community-supported software for describing and comparing microbial communities. Appl. Environ. Microbiol. 75 (23), 7537-7541. https://doi.org/10.1128/AEM.01541-09.

Schratzberger, M., Ingels, J., 2018. Meiofauna matters: the roles of meiofauna in benthic ecosystems. J. Exp. Mar. Biol. Ecol. 502, 12-25. https://doi.org/10.1016/j. jembe.2017.01.007.

Sinniger, F., Pawlowski, J., Harii, S., Gooday, A.J., Yamamoto, H., Chevaldonné, P., Cedhagen, T., Carvalho, G., Creer, S., 2016. Worldwide analysis of sedimentary DNA reveals major gaps in taxonomic knowledge of deep-sea benthos. Front. Mar. Sci. 3, 92. https://doi.org/10.3389/fmars.2016.00092.

Somerfield, P.J., Warwick, R.M., 2013. Meiofauna techniques. In: Elefthriou, A. (Ed.), Methods for the Study of Marine Benthos. John Wiley \& Sons, Ltd, pp. 253-284. https://doi.org/10.1002/9781118542392.ch6.

Sousa, R., Dias, S., Antunes, J.C., 2006. Spatial subtidal macrobenthic distribution in relation to abiotic conditions in the Lima estuary, NW of Portugal. Hydrobiologia 559, 135-148. https://doi.org/10.1007/s10750-005-1371-2.

Sousa, R., Dias, S., Antunes, C., 2007. Subtidal macrobenthic structure in the lower lima estuary, NW of Iberian Peninsula. Aquat. Conserv. Ann Zool Fennici 44 (4), 303-313. https://doi.org/10.1002/aqc.

Stoeck, T., Bass, D., Nebel, M., Christen, R., Jones, M.D.M., Breiner, H.W., Richards, T.A., 2010. Multiple marker parallel tag environmental DNA sequencing reveals a highly complex eukaryotic community in marine anoxic water. Mol. Ecol. 19, 21-31. https://doi.org/10.1111/j.1365-294X.2009.04480.x.

Sun, P., Huang, L., Xu, D., Huang, B., Chen, N., Warren, A., 2017. Marked seasonality and high spatial variation in estuarine ciliates are driven by exchanges between the 'abundant' and 'intermediate' biospheres. Sci. Rep. 7, 1-12. https://doi.org/ 10.1038/s41598-017-10308-y.

Sweetman, A.K., Thurber, A.R., Smith, C.R., Levin, L.A., Mora, C., Wei, C.-L., Gooday, A. J., Jones, D.O.B., Rex, M., Yasuhara, M., Ingels, J., Ruhl, H.A., Frieder, C.A., Danovaro, R., Würzberg, L., Baco, A., Grupe, B.M., Pasulka, A., Meyer, K.S., Dunlop, K.M., Henry, L.-A., Roberts, J.M., 2017. Major impacts of climate change on deep-sea benthic ecosystems. Elem Sci Anth 5 (4), 1-23. https://doi.org/10.1525/ elementa.203.

Tang, C.Q., Leasi, F., Obertegger, U., Kieneke, A., Barraclough, T.G., Fontaneto, D., 2012. The widely used small subunit $18 \mathrm{~S}$ rDNA molecule greatly underestimates true diversity in biodiversity surveys of the meiofauna. Proc. Natl. Acad. Sci. Unit. States Am. 109 (40), 1620816212. https://doi.org/10.1073/pnas.1209160109.

Thompson, G.G., Withers, P.C., 2003. Effect of species richness and relative abundance on the shape of the species accumulation curve. Austral Ecol. 28, 355-360. https:// doi.org/10.1046/j.1442-9993.2003.01294.x.

Thompson, G.G., Withers, P.C., Pianka, E.R., Thompson, S.A., 2003. Assessing biodiversity with species accumulation curves; inventories of small reptiles by pittrapping in Western Australia. Austral Ecol. 28, 361-383. https://doi.org/10.1046/ j.1442-9993.2003.01295.x.

Thompson, G.G., Thompson, S.A., Withers, P.C., Fraser, J., 2007. Determining adequate trapping effort and species richness using species accumulation curves for environmental impact assessments. Austral Ecol. 32, 570-580. https://doi.org/ 10.1111/j.1442-9993.2007.01729.x.

Udden, J.A., 1914. Bulletin of the geological society of America. Geol. Soc. Am. Bull. 25, 655-744.

Wang, J.F., Stein, A., Gao, B.B., Ge, Y., 2012. A review of spatial sampling. Spat. Stat. 2, 1-14. https://doi.org/10.1016/j.spasta.2012.08.001.

Wangensteen, O.S., Palacín, C., Guardiola, M., Turon, X., 2018. DNA metabarcoding of littoral hard-bottom communities: high diversity and database gaps revealed by two molecular markers. PeerJ 6, e4705. https://doi.org/10.7717/peerj.4705.

Warwick, R., Gee, J., 1984. Community structure of estuarine meiobenthos. Mar. Ecol. Prog. Ser. 18, 97-111. https://doi.org/10.3354/meps018097.

Weigand, H., Beerman, A.J., Ciampor, F., Costa, F.O., Csabai, Z., Duarte, S., Geiger, M.F., Grabowski, M., Rimet, F., Rulik, B., Strand, M., Szucsich, N., Weigand, A.M., Willansen, En, Wyler, S.A., Bouchez, A., Borja, A., Čiamporová-Zatovičová, Z., Ferreira, S., Dijkstra, KD.B., Eisendle, U., Freyhof, J., Gadawski, P., Graf, W., Haegerbaeumer, A., van der Hoorn, B.B., Japoshvili, B., Keresztes, L., Keskin, E., Leese, F., Macher, J.P., Mamos, T., Paz, G., Pešić, V., Pfannkuchen, D.M., Pfannkuchen, M.A., Price, B.W., Rinkevich, B., Teixeira, M.A.L., Várbíró, G., Ekrem, T., 2019. DNA barcode reference libraries for the monitoring of aquatic biota in Europe: Gap-analysis and recommendations for future work. Science of the Total Environment 678, 499-524. https://doi.org/10.1016/j.scitotenv.2019.04.247.

Weigand, A.M., Macher, J.-N., 2018. A DNA metabarcoding protocol for hyporheic freshwater meiofauna: evaluating highly degenerate COI primers and replication strategy. Metabarcoding and Metagenomics 2, 1-15. https://doi.org/10.3897/ mbmg.2.26869.

Wentworth, C.K., 1922. A scale of grade and class terms for clastic sediments. J. Geol. 30, 377-392. https://doi.org/10.1086/622910.

Zeppilli, D., Leduc, D., 2018. Biodiversity and ecology of meiofauna in extreme and changing environments. Mar. Biodivers. 48, 1-4. https://doi.org/10.1007/s12526017-0840-y.

Zeppilli, D., Sarrazin, J., Leduc, D., Arbizu, P.M., Fontaneto, D., Fontanier, C., Gooday, A. J., Kristensen, R.M., Ivanenko, V.N., Sørensen, M.V., Vanreusel, A., Thébault, J., Mea, M., Allio, N., Andro, T., Arvigo, A., Castrec, J., Danielo, M., Foulon, V., Fumeron, R., Hermabessiere, L., Hulot, V., James, T., Langonne-Augen, R., Le Bot, T., Long, M., Mahabror, D., Morel, Q., Pantalos, M., Pouplard, E., Raimondeau, L., RioCabello, A., Seite, S., Traisnel, G., Urvoy, K., Van Der Stegen, T., Weyand, M., Fernandes, D., 2015. Is the meiofauna a good indicator for climate change and anthropogenic impacts? Mar. Biodivers. 45, 505-535. https://doi.org/10.1007/ s12526-015-0359-z. 